Int. J. Electrochem. Sci., 15 (2020) 929 - 946

International Journal of

ELECTROCHEMICAL

SCIENCE

$\underline{\text { WWW.electrochemsci.org }}$

\title{
3D Network Conductive Polymer/Pt Composites as Elcetrocatalyst for Methanol Oxidation
}

\author{
Maodan Xu ${ }^{1}$, Yongquan Qing ${ }^{2}$,Yanbin Yin ${ }^{1}$, Shiyun Ai ${ }^{1}$, Junling Duan ${ }^{1}$, Houshen $\mathrm{Li}^{1, *}$ and Yijing $\mathrm{Li}^{1, *}$ \\ ${ }^{1}$ College of Chemistry and Material Science, Shandong Agricultural University, Taian, Shandong, \\ 271018, PR China. \\ ${ }^{2}$ Key Laboratory for Anisotropy and Texture of Materials, Ministry of Education, Northeastern \\ University, Shenyang 110819, China. \\ *E-mail: hsli@sdau.edu.cn, yjli@sdau.edu.cn
}

doi: $10.20964 / 2020.01 .82$

Received: 3 September 2019 / Accepted: 29 October 2019 / Published: 30 November 2019

\begin{abstract}
Methanol oxidation is a fatal reaction for developing methanol-based fuel cell, which is an potential choice for solving energy crisis. Here, we developed a simple and efficient strategy for synthesis of three-dimensional (3D) network polyaniline (PANI) gel which was used as conductive matrix for methanol oxidation. Then, we systematically compared the electrochemical activity of differently shaped Pt nanomaterials. Due to the combination of the specific structure of Pt nanomaterial, conducting properties and large surface of 3D network PANI, 3D PANI/Pt NCs catalyst shows excellent electrocatalysis performance. In comparison with commercial Pt black, hyperbranched Pt NCs, and other structure PANI/Pt NCs, the 3D network PANI/Pt NCs have superior catalytic activity and stability towards methanol oxidation. The catalytic activity of 3D network PANI/Pt NCs was 2.92 times higher than that of the commercial Pt black. Besides, the original 3D network PANI also shows well Cr(VI) removal properties due to its large surface area and abundant active sites. Meanwhile, the 3D network PANI with simple fabrication process and excellent performance may have great potential in electrochemical applications and biosensors.
\end{abstract}

Keywords: energy crisis, fuel cell, Pt, conductive polymer, heavy metal removal.

\section{$\underline{\text { FULL TEXT }}$}

(C) 2020 The Authors. Published by ESG (www.electrochemsci.org). This article is an open access article distributed under the terms and conditions of the Creative Commons Attribution license (http://creativecommons.org/licenses/by/4.0/). 